\title{
O ASSistente social e a política de atenção à saúde PRISIONAL: UM ESTUDO APROXIMATIVO
}

\author{
THE SOCIAL WORKER AND THE HEALTH CARE PRISION POLICY:
}

AN APPROXIMATE STUDY

Glauco Pereira de Oliveira e Braga ${ }^{1}$

\begin{abstract}
RESUMO
O texto tem como objetivo conhecer de forma aproximativa os caminhos que estabeleceram a inserção do assistente social na nova lógica de atenção e organização dos serviços de saúde, no âmbito prisional, estabelecida na atual Política de Atenção à Saúde Prisional: a Política Nacional de Atenção Integral à Saúde das Pessoas Privadas de Liberdade no Sistema Prisional (PNAISP). Para o estudo utilizou-se da pesquisa exploratória a partir de revisão bibliográfica de fontes recentes (2014-2105). O estabelecimento da saúde como um direito de todos e a criação do Sistema Único de Saúde (SUS) foram momentos marcantes para a atuação do assistente social e para a atenção à saúde desse grupo populacional. Considerando um breve histórico das políticas de atenção à saúde no âmbito prisional, o texto discutirá elementos inerentes ao tema e à atuação profissional na atenção à saúde das pessoas privadas de liberdade a qual deve estar arraigada nos pressupostos contidos no projeto ético-político profissional. Permeada pelo contexto histórico da construção do SUS, do Serviço Social na relação com a saúde e das políticas de atenção à saúde prisional, a PNAISP, promulgada em 2014, promove a abertura de uma nova lógica de atuação profissional, no contexto prisional. A atuação do assistente social nessa proposta vincula-se à perspectiva do SUS, da atenção primária à saúde e aos processos de trabalho coletivo em saúde, sendo permeada pelo tensionamento entre perspectivas do campo da saúde, justiça bem como do sistema penitenciário.
\end{abstract}

PALAVRAS-CHAVE: Assistente social. Atuação profissional. Política de Atenção à Saúde Prisional. PNAISP. Saúde prisional.

\footnotetext{
${ }^{1}$ Universidade Federal de Santa Catarina. Bacharel em Serviço Social pela Universidade Federal de Santa Catarina. Especialista em Serviço Social: Direitos Sociais, Fundamentos da Profissão e Competências Profissionais pelo Centro Universitário UNINTER. Assistente social da Universidade Federal de Santa Catarina. Telefone: 47 9957-4556. E-mail: glbraga7@gmail.com.
} 


\begin{abstract}
The text aims to know approximated the ways that established the insertion of the social worker in the new logic of care and organization of health services in the prison context, introduced in the current prisional health care policy: the National Integral Health Care Policy of Persons Deprived of Liberty in Prison System. For the study we used the exploratory research from literature review of recent sources (2014-2105). The establishment of health as a right for all and the creation of the Brazilian Unified Health System (UHS) were important moments for the role of the social worker and the health care of this population group. Considering a brief history of health care policies in the prison context, the paper discusses elements inherent to the subject and professional practice in the health care of persons deprived of liberty which must be rooted to the assumptions contained in the professional ethical-political project. Permeated by the historical context of Brazilian Unified Health System construction, of Social Service in relation to health area and of attention to the prison health policies, the current health care policy in prision context, enacted in 2014, promotes the opening of a new logic professional performance in the prison context. The role of the social worker in this proposal is linked to UHS perspective, the primary health care and collective work processes in health, being pervaded by tension between health area perspective, justice and the prison system.
\end{abstract}

KEYWORDS: Social Worker. Professional Exercise. Prision System Health Care Policy.

PNAISP. Prision Health

\title{
INTRODUÇÃO
}

Conforme a atual política de atenção à saúde prisional (BRASIL, 2014b), os serviços de saúde nos estabelecimentos prisionais serão prestados por equipes multiprofissionais, denominadas Equipes de Saúde no Sistema Prisional (ESP), regulamentadas a partir da Política Nacional de Atenção Integral à Saúde das Pessoas Privadas de Liberdade no Sistema Prisional (PNAISP).

O presente artigo pretende proporcionar um estudo aproximativo sobre a inserção do assistente social nessas equipes, conforme a nova política de atenção à saúde das pessoas privadas de liberdade. Por se tratar de uma política instituída recentemente, em 2014, é fundamental conhecer, mesmo que de forma introdutória, os caminhos que estabeleceram a inserção do assistente social nessa nova proposta de atenção e organização dos serviços de saúde bem como problematizar e apresentar elementos inerentes ao tema, como o histórico das políticas de atenção à saúde no âmbito prisional.

A escassa produção bibliográfica do Serviço Social em torno da recente política de saúde prisional; o fato de a mesma estar em fase de implementação; a recente inserção de profissionais do Serviço Social em equipes de saúde no sistema prisional e a importância de se produzir conhecimento e atualizar as discussões em torno de temas Serv. Soc. \& Saúde, Campinas, SP v.15, n. 2 (22), p. 219-242, jul./dez. 2016 ISSN 1676-6806 
contemporâneos que se apresentam ao Serviço Social, demonstram a importância desse estudo aproximativo à categoria profissional.

Espera-se que o texto contribua de forma inicial com as discussões em torno da temática apresentando, brevemente, aspectos fundamentais de debate para o assistente social que está inserido ou se inserindo nos serviços de saúde no âmbito prisional. O fato de ter atuado em uma equipe de saúde prisional, nos moldes preconizados pela atual política de atenção a saúde prisional, motivou o autor a esboçar um texto aproximativo sobre o tema, a partir de pesquisa exploratória utilizando-se de revisão bibliográfica de fontes recentes, entre 2014 e 2015, e legislações relacionadas à PNAISP, localizadas através de base de dados e ferramentas de pesquisa online. Além disso, para a elaboração do texto considerou-se a realidade vivenciada na breve experiência do autor na atuação como assistente social em uma equipe de saúde no sistema prisional.

A proposta do estudo considera o Serviço Social como uma profissão "que se particulariza na divisão social e técnica do trabalho pelo seu trato com a questão social, expressão da desigualdade do modo de acumulação capitalista” (MATOS, 2013, p. 55). Além disso, o presente artigo estabelece o assistente social, inserido nas equipes de saúde do sistema prisional, como um profissional da saúde no processo de trabalho coletivo em saúde. Dessa forma, o texto abordará a profissão na relação com o Sistema Único de Saúde e da atenção primária em saúde ${ }^{2}$, com a perspectiva dos Parâmetros de Atuação do Assistente Social na política de saúde ${ }^{3}$, na qual se situa a Política Nacional de Atenção Integral à Saúde das Pessoas Privadas de Liberdade no Sistema Prisional.

\footnotetext{
${ }^{2}$ Apesar de o texto utilizar os termos “atenção primária” e “atenção básica”, em diferentes momentos, referindo-se à atenção à saúde, o uso desses dois conceitos remete a perspectiva de atenção básica expressada na Política de Atenção Básica - PNAB (2012a). Nesse estudo, são considerados como sinônimo. Para se aprofundar no assunto, ver Gil (2006) que analisa esses conceitos em seu texto: Atenção Primária, atenção básica e saúde da família: sinergias e singularidades do contexto brasileiro. ${ }^{3}$ Os ‘Parâmetros para a Atuação de Assistentes Sociais na Política de Saúde’ é um documento publicado pelo Conselho Federal de Serviço Social em 2010, e segundo o próprio órgão, “tem como finalidade referenciar a intervenção dos profissionais de Serviço Social na área da saúde. Constitui-se como produto do Grupo de Trabalho "Serviço Social na Saúde”, instituído pelo Conselho Federal de Serviço Social (CFESS) em 2008”. O documento está disponível em $<$ http://www.cfess.org.br/arquivos/Parametros_para_a_Atuacao_de_Assistentes_Sociais_na_Saude.pdf> Serv. Soc. \& Saúde, Campinas, SP v.15, n. 2 (22), p. 219-242, jul./dez. 2016 ISSN 1676-6806
} 


\section{O SISTEMA ÚNICO DE SAÚDE, A ATENÇÃO BÁSICA E O SERVIÇO SOCIAL: BASES PARA A INSERÇÃOO PROFISSIONAL NA PNAISP}

O Sistema Único de Saúde (SUS) efetivou-se a partir de um contexto de lutas sociais, em uma década marcada pelo fim da ditadura militar, pela atuação do Movimento da Reforma Sanitária e disputa acirrada de projetos societários no Brasil. Segundo Vasconcellos e Pasche (2006, p. 532), esse sistema

[...] é um produto da Reforma Sanitária Brasileira, originada do movimento sanitário, processo político que mobilizou a sociedade brasileira para propor novas políticas e novos modelos de organização de sistemas, serviços e práticas de saúde.

Apesar de a saúde pública brasileira ter seus contornos iniciados no século XIX e o Ministério da Saúde no início da década de 1950, a saúde somente é reconhecida como um direito social na Constituição Federal Brasileira de 1988, inserida assim como parte da Seguridade Social brasileira.

A atual constituição brasileira institui, no artigo 196, que a saúde é "direito de todos e dever do Estado, garantido mediante políticas sociais e econômicas que visem à redução do risco de doença e de outros agravos e ao acesso universal e igualitário às ações e serviços para a promoção, proteção e recuperação" (BRASIL, 1998). Segundo Vasconcellos e Pasche (2006, p. 532) "a inserção no contexto constitucional da saúde como direito de cidadania e dever do Estado, [...] realçou e deu força jurídica de relevância pública às ações e serviços de saúde”.

Na década de 1990, foi aprovado pelo Congresso Nacional a Lei Orgânica da Saúde (LOS) que tratou sobre a operacionalização do SUS, conhecida como a Lei $8.080^{4}$. Além disso, a Lei $1.842^{5}$ foi promulgada para dar diretrizes às transferências de recursos e estabelecer a participação social. Essa duas leis inauguram e estabelecem "os

\footnotetext{
${ }^{4}$ A lei no 8.080 , de 19 de setembro de 1990 dispõe sobre as condições para a promoção, proteção e recuperação da saúde, a organização e o funcionamento dos serviços correspondentes e dá outras providências. [http://www.planalto.gov.br/ccivil_03/leis/L8080.htm]

${ }^{5}$ A lei $n^{\circ}$ 8.142, de 28 de dezembro de 1990 dispõe sobre a participação da comunidade na gestão do Sistema Único de Saúde (SUS) e sobre as transferências intergovernamentais de recursos financeiros na área da saúde e dá outras providências. Disponível em

[http://conselho.saude.gov.br/legislacao/lei8142_281290.htm] Acesso em 1 de jul de 2015.
} 
marcos legais básicos que fixam os fundamentos tanto valorativos quanto políticos e organizacionais da política de saúde” (FLEURY; OUVERNEY, 2012, p. 34).

A partir das regulamentações ocorridas após a Constituição Federal de 1988 na área da saúde e do processo histórico da criação e gestão do Sistema Único de Saúde, definiram-se e foram delineados os níveis de atenção à saúde. Os serviços configuraram-se de forma hierárquica sendo a Atenção Básica o primeiro nível de atenção. Um importante passo para o fortalecimento da atenção básica está na elaboração da Política Nacional da Atenção (PNAB) cujo processo de instituição é "resultado da experiência acumulada de vários atores envolvidos historicamente com o desenvolvimento e a consolidação do Sistema Único de Saúde (SUS) [...]” (BRASIL, 2012a, p. 9).

A atenção primária orienta-se pelos princípios do SUS, tais como a universalidade, integralidade e participação da comunidade e se fundamenta nos princípios da humanização, acessibilidade, cuidado integral e coordenação do cuidado. Esse nível de atenção à saúde é caracterizado como

[...] um conjunto de ações de saúde, no âmbito individual e coletivo, que abrange a promoção e a proteção da saúde, a prevenção de agravos, o diagnóstico, o tratamento, a reabilitação, a redução de danos e a manutenção da saúde com o objetivo de desenvolver uma atenção integral que impacte na situação de saúde e autonomia das pessoas e nos determinantes e condicionantes de saúde das coletividades (BRASIL, 2012a, p.19).

De forma sucinta foram apresentadas características e um breve histórico sobre a atenção primária a saúde, nível de atenção que norteará a atuação das equipes de saúde do sistema prisional, que se delineou após a constituição da saúde como direito, do Sistema Único de Saúde e das regulamentações posteriores.

O processo de democratização brasileira e da luta dos movimentos sociais, mencionados anteriormente, não só possibilitou a abertura para a criação do SUS como também se tornou fundamental na ampliação do campo de atuação do Serviço Social na área da saúde.

A descentralização político-administrativa brasileira promovida pela Constituição Federal de 1998, com “direção única em cada esfera de governo” (BRASIL, 1988) desencadeou o processo de municipalização de serviços de saúde que 
se tornou um movimento importante para o assistente social. Segundo Kruger $\left(2010^{\mathrm{a}}\right)$, “esta descentralização administrativa tem proporcionado uma crescente ampliação do mercado de trabalho para as profissões da área da saúde na esfera municipal, entre elas o Serviço Social” (ibid., p. 131).

O Serviço Social é uma profissão que tem na atenção básica espaços sócioocupacionais constituídos pelo processo histórico da construção do SUS, da própria profissão e da descentralização político-administrativa do Brasil. As equipes de atenção à saúde prisional, preconizadas pela atual política de saúde prisional, estão inseridas, em certa medida, nesse movimento, pois a partir da PNAISP os municípios que aderirem à política assumirão responsabilidades referentes à atenção à saúde das pessoas privadas de liberdade seja no âmbito da execução, gestão, organização ou cooperação com as equipes.

Moscon; Kruger (2010b), apontam que na Atenção Básica chegam para o assistente social

[...] as tradicionais demandas às quais se mesclam entre necessidades sociais e de saúde. Este amplo leque de demandas expressa necessidades de saúde no conceito ampliado do SUS. Portanto, o conjunto dessas necessidades revela a enorme carência de proteção social em que vive grande parte da população (ibid., p. 88).

A atuação do assistente social, nesse nível de atenção à saúde, é permeada por um processo de trabalho interdisciplinar bem como multiprofissional e contribui para a efetivação da participação social, controle social e da integralidade de assistência, através da articulação das demandas espontâneas e individuais, planejamento, programação e da promoção de ações de promoção, prevenção, vigilância à saúde, tratamento e avaliação e monitoramento das ações e dos resultados (KRUGER, 2010a).

A municipalização oriunda das diretrizes da Constituição Federal Brasileira e as mudanças no conceito (ampliado) e acesso à saúde, principalmente no âmbito peculiar do sistema penitenciário, alteram “o perfil e as necessidades de saúde dos usuários” bem como demandam profissionais “não médicos”, nos termos de Moscon; Kruger (2010b), sendo o assistente social um deles. Nesse viés se apresenta a necessidade e importância do Serviço Social nas equipes de atenção em saúde, principalmente no contexto prisional.

Serv. Soc. \& Saúde, Campinas, SP v.15, n. 2 (22), p. 219-242, jul./dez. 2016 ISSN 1676-6806 
Dessa forma, tem-se brevemente um panorama da atuação do Serviço Social na atenção básica que se dá, entre outros meios, através de processos de coordenação, gestão e planejamento, principalmente pelas possibilidades que os processos de trabalho multiprofissionais, interdisciplinares e intersetorial propõem e permitem à atuação profissional (MOSCON; KRUGER, 2010b). De acordo com Mioto e Nogueira (2006) há três processos básicos que integram o processo de trabalho em saúde, os quais se articulam entre si e contribuem para a análise da atuação do Serviço Social nas equipes de saúde prisional, são eles: Os Processos Político-organizativos, Processos de Planejamento e Gestão, Processos Socioassistenciais ${ }^{6}$.

Ao se considerar o tema da municipalização decorrente dos processos de descentralização político-administrativos e organização dos serviços de saúde a partir do Sistema Único de Saúde, o processo histórico do Serviço Social e da atenção à saúde da população privada de liberdade, percebe-se um espaço de atuação que se estabelece aos assistentes sociais e a outros profissionais de saúde: a atenção à saúde das pessoas privadas de liberdade no sistema prisional brasileiro, no âmbito do SUS e da atenção primária à saúde.

\section{CAMINHOS DA POLÍTICA DE ATENÇÃO À SAÚdE NO CONTEXTO PRISIONAL E O SERVIÇO SOCIAL}

Podem-se estabelecer historicamente três relevantes marcos regulatórios no que tange a propostas relacionadas à atenção a saúde das pessoas privadas de liberdade (LERMEN et al., 2015; BARSAGLINI et al., 2015; SILVEIRA, 2015): 1) A Lei de Execução Penal $(\mathrm{LEP})^{7}$, de 1984,2$)$ o Plano Nacional de Saúde no Sistema Penitenciário (PNSSP), de 2003 e 3) a Política Nacional de Atenção Integral à Saúde das Pessoas Privadas de Liberdade no Sistema Prisional (PNAISP), de 2014.

\footnotetext{
${ }^{6}$ Esses três processos interventivos da ação profissional são trabalhados pelas autoras Vera Maria Ribeiro Nogueira e Regina Célia Tamaso Mioto no texto: Sistematização, planejamento e avaliação das ações dos assistentes sociais no campo da saúde. MOTA, A. E. et al. (Org.). Serviço Social e saúde: formação e trabalho profissional. São Paulo: OPAS, OMS, MS, Cortez, p. 273-303, 2006.

${ }^{7}$ A Lei de Execução Penal foi instituída pela lei no 7.210, de 11 de julho, de 1984. Segundo o documento, a execução penal tem por objetivo efetivar as disposições de sentença ou decisão criminal e proporcionar condições para a harmônica integração social do condenado e do internado. Segundo Lermen et al. (2015, p. 909) "a LEP fundamenta os direitos, deveres, sanções da disciplina e avaliação dos presos, tendo como foco a reintegração social, que busca a prevenção do crime e a preparação da pessoa presa para o retorno ao convívio social (BRASIL, 1984)".

Serv. Soc. \& Saúde, Campinas, SP v.15, n. 2 (22), p. 219-242, jul./dez. 2016 ISSN 1676-6806
} 
A Lei de Execução Penal prevê a assistência material, jurídica, educacional, social, religiosa e o direito, porém com uma perspectiva fragmentada e curativa de saúde. De acordo com essa lei, “a assistência à saúde do preso e do internado de caráter preventivo e curativo, compreenderá atendimento médico, farmacêutico e odontológico” (BRASIL, 1984). O assistente social não aparece diretamente vinculado à área da saúde. Indiretamente o profissional insere-se na Seção VI, da Assistência Social, conforme o seguinte trecho da Lei de Execução Penal (BRASIL, 1984):

Art. 22. A assistência social tem por finalidade amparar o preso e o internado e prepará-los para o retorno à liberdade.

Art. 23. Incumbe ao serviço de assistência social:

I - conhecer os resultados dos diagnósticos ou exames;

II - relatar, por escrito, ao Diretor do estabelecimento, os problemas e as dificuldades enfrentadas pelo assistido;

III - acompanhar o resultado das permissões de saídas e das saídas temporárias;

IV - promover, no estabelecimento, pelos meios disponíveis, a recreação;

V - promover a orientação do assistido, na fase final do cumprimento da pena, e do liberando, de modo a facilitar o seu retorno à liberdade; VI - providenciar a obtenção de documentos, dos benefícios da Previdência Social e do seguro por acidente no trabalho;

VII - orientar e amparar, quando necessário, a família do preso, do internado e da vítima.

Não é a proposta desse estudo estabelecer as delimitações da atuação do assistente social vinculado a uma equipe básica de saúde prisional e do assistente social vinculado aos processos de trabalho de uma unidade prisional, porém é importante a discussão dos processos de trabalho desses dois espaços sócio-ocupacionais de atuação profissional. Sendo assim, não serão propostas reflexões e implicações com o trabalho do Serviço Social no âmbito exclusivo de unidades prisionais (presídios e penitenciárias, por exemplo) as quais tem como parâmetros de atuação as discussões da profissão no âmbito sociojurídico ${ }^{8}$ no qual se incluem espaços de atuação profissional de natureza jurídica. Porém, é importante que estudos futuros abordem essa questão. Sendo assim, será fundamental a discussão coletiva e a proposição de estudos sobre o direcionamento, aproximações e parâmetros de atuação do assistente social vinculado

\footnotetext{
${ }^{8}$ Para compreender o Serviço Social no âmbito sociojurídico o texto publicado pelo Conselho Federal de Serviço Social - CFESS, em 2014, “A atuação de assistentes sociais no sociojurídico: subsídios para reflexão” é de suma relevância. O texto é um documento que objetiva qualificar e referenciar a intervenção dos profissionais de Serviço Social nesse âmbito e pode ser acessado em <http://www.cfess.org.br/arquivos/CFESSsubsidios_sociojuridico2014.pdf> Serv. Soc. \& Saúde, Campinas, SP v.15, n. 2 (22), p. 219-242, jul./dez. 2016 ISSN 1676-6806
} 
diretamente ao âmbito prisional e do profissional a partir da atuação em equipes de saúde no sistema prisional, no contexto do SUS.

É importante observar que a década de 1980 foi marcada pelo fim do período da ditadura militar, pelo movimento de Reforma Sanitária brasileira, pela realização da $8^{\text {a }}$ Conferência Nacional de Saúde e pelo movimento histórico de promulgação da Constituição Federal (BRASIL, 1988). A LEP foi instituída em 1984; o texto dessa lei carrega uma perspectiva não condizente ao Movimento de Reforma Sanitária e encontra-se em um contexto anterior ao estabelecimento da saúde como direito, nos termos da Constituição Federal. A saúde é voltada ao modelo médico-centrado, porém no que tange a proposta de atenção à saúde da população privada de liberdade constituise um importante passo para a compreensão da saúde como um direito dessa população.

Sobre o período entre a instituição da Lei de Execução Penal (BRASIL, 1984) e a promulgação da Constituição Federal do Brasil (BRASIL, 1988), Silveira (2015) caracteriza a prestação de serviço à saúde prisional mencionando que

[...] não há registro de avanços legais na área da saúde prisional. Além disso, na prática da Lei de execução penal houve pouca ou nenhuma consolidação desta Lei e a prestação de serviços de saúde, de 1984 até os anos 90 foi estruturada com hospitais penitenciários montados em cada estado, cada uma a seu critério, sem políticas ou planos específicos, sendo assim os avanços legais são pontuais em cada Estado (ibid., p. 17).

A mesma autora complementa a análise sobre esse momento histórico da atenção à saúde das pessoas privadas de liberdade concluindo que

[...] o que se observa nesse período de 1984 (LEP) aos anos 90 é que havia atendimento aos apenados, mas que eram realizados a título de emergência em hospitais penitenciários, sem preocupação com prevenção e promoção de saúde e com recursos do Estado e pelas Secretarias de Justiça, sem regras específicas e sem financiamentos específicos, já que o dever de promover saúde era de quem tinha a tutela do apenado, no caso, o Estado, as unidades prisionais que existiam realizam atendimento cada um a seu critério, sem políticas resolutivas (SILVEIRA, 2015, p. 23).

A Lei de Execuções Penais (1984), apesar de se constituir em um importante marco regulatório no sentido de garantia do direito à saúde da população privada de liberdade, é insuficiente e não abarca toda a complexidade que o acesso a esse direito implica. Sendo assim, tornou-se necessário uma política ou plano que de forma mais 
consistente apresentasse uma proposta para garantir efetivamente o direito à saúde através de ações e processos organizativos que contemplassem através de outra perspectiva o processo saúde-doença.

Considerando a análise dos dados do Sistema de Informações Penitenciárias (INFOPEN) ${ }^{9}$, Coelho et al. (2014, p. 9) expõe que ”[...] a população prisional no Brasil em 2009 era de 473.626 pessoas, sendo 442.225 homens e 31.401 mulheres, e está em crescimento acentuado".

Se observarmos os dados atuais, principalmente do relatório do INFOPEN de 2014, encontraremos números mais expressivos. Segundo os dados desse relatório a população prisional estava em 607.731, considerando os estabelecimentos penais (BRASIL, 2014a). Esse fato implica em um contexto que leva à superpopulação do sistema penitenciário e implica em diversas consequências oriundas da expressão da questão social. Porém, o atual contexto do sistema penitenciário não pode ser acompanhado da redução de acesso ao direito à saúde em seu sentido mais amplo. Sendo assim,

[...] para enfrentar essa realidade, foram estruturadas políticas públicas de saúde para atender às necessidades do sistema prisional brasileiro, que preveem a implantação de equipes de saúde específicas para essas instituições. Dessa maneira, busca-se garantir o direito constitucional de acesso universal a ações e serviços saúde, para efetivar os direitos sociais previstos por lei às pessoas privadas de liberdade [...] (COELHO et al., 2014, p. 9).

Nessa perspectiva se apresenta o segundo marco regulatório, instituído após a LEP, no que tange às políticas de saúde voltadas às pessoas privadas de liberdade: o Plano Nacional de Saúde no Sistema Penitenciário (PNSSP). Previsto pela portaria Interministerial $\mathrm{n}^{0}$ 1.777, aprovada em 2003, o plano é “destinado a prover a atenção integral à saúde da população prisional confinada em unidades masculinas e femininas, bem como nas psiquiátricas” (BRASIL, 2004, p. 22).

Segundo Coelho et al. (2014, p. 11),

\footnotetext{
${ }^{9}$ O Sistema Integrado de Informações Penitenciárias (INFOPen), disponível para consulta no portal eletrônico do Ministério da Justiça <http://portal.mj.gov.br>, consiste no Sistema de Informações do Ministério da Justiça para o Sistema Penitenciário do Brasil. Tem como objetivo subsidiar o planejamento de políticas públicas para o setor.

Serv. Soc. \& Saúde, Campinas, SP v.15, n. 2 (22), p. 219-242, jul./dez. 2016 ISSN 1676-6806
} 
O PNSSP foi instituído considerando justamente as condições desfavoráveis de higiene e salubridade da maioria das unidades prisionais no país, bem como as elevadas taxas de prevalência de infecção por HIV/Aids, tuberculose, hepatites e outras doenças sexualmente transmissíveis e infectocontagiosas no sistema penitenciário nacional. Tal quadro contrasta com os dados gerais da população brasileira. Nestes, de maneira geral, há uma maior incidência de doenças crônicas não transmissíveis (DCNT) frente às infectocontagiosas e parasitárias.

No PNSSP se pôs a necessidade de se estabelecer ações de saúde no sistema penitenciário brasileiro na perspectiva do SUS. Lermen et al. (2015) propõem uma comparação desse plano em relação a LEP, mencionando principalmente a mudança de termos utilizados para denominar as pessoas privadas de liberdade, promovendo assim uma ampliação ao direito à saúde e na percepção em relação aos sujeitos privados de liberdade.

Ao analisarmos o texto do Plano, identificamos que há uma mudança no que se refere aos termos empregados para identificar a população penitenciária: a inclusão das expressões "pessoas privadas de liberdade” e "população confinada nas unidades prisionais", embora se tenha mantido o termo "preso", tendo sido excluída somente a designação “condenado” (LERMEN et al., 2015, p. 910).

O PNSPP cuja vigência se deu até o ano de 2013 foi um documento que balizou e instituiu de forma mais sistematizada a atenção à saúde das pessoas privadas de liberdade. “As ações e serviços decorrentes desse Plano terão por finalidade promover a saúde dessa população e contribuir para o controle e/ou redução dos agravos mais frequentes que a acometem” (BRASIL, 2004, p.22). As ações e serviços objetivavam atender com prioridade

[...] a reforma e a equipagem das unidades prisionais visando a estruturação de serviços ambulatoriais que atendam às necessidades de atenção no nível básico, mínimo da assistência no nível da média complexidade (conforme NOAS/MS em seu Anexo III - Grupo 7) e componentes das urgências e emergências em saúde, em consonância com as especificidades do Sistema Penitenciário Nacional; II - a organização do sistema de informação de saúde da população penitenciária; III - a implantação de ações de promoção da saúde, em especial no âmbito da alimentação, atividades físicas, condições salubres de confinamento e acesso a atividades laborais; IV - a implementação de medidas de proteção específica, como a vacinação contra hepatites, influenza, tétano; V - a implantação de ações para a prevenção de tuberculose, hanseníase, diabetes, hipertensão, hepatites, DST/Aids e dos agravos psicossociais decorrentes do confinamento, bem como a distribuição de preservativos e insumos para a redução de danos associados ao uso de drogas; VI - a garantia do acesso da

Serv. Soc. \& Saúde, Campinas, SP v.15, n. 2 (22), p. 219-242, jul./dez. 2016 ISSN 1676-6806 
população penitenciária aos demais níveis de atenção à saúde, através das referências, que deverão estar incluídas na Programação Pactuada Integrada (PPI) estadual, mediante negociação na Comissão Intergestores Bipartite (CIB) (BRASIL, 2004, p. 22).

Nessa perspectiva apresentada pelo plano, a atenção à saúde também abrange, mesmo que de forma mínima, a atenção considerada de média complexidade e processos de urgência e emergência em saúde. Lermen et al. (2015, p. 912) ao citarem o PNSSP referem que além der se constituir um marco legal referente a política de saúde prisional representa uma "nova perspectiva de saúde no sistema penitenciário”. No oitavo artigo da portaria que institui o plano, estabelece-se ainda que "a atenção básica de saúde será realizada por equipe mínima, integrada por médico, enfermeiro, odontólogo, assistente social, psicólogo, auxiliar de enfermagem e auxiliar de consultório dentário [...]” (BRASIL, 2004). Logo, observa-se a inserção do Serviço Social de forma direta na atenção à saúde das pessoas privadas de liberdade, no sistema penitenciário brasileiro, e a importância da presença do profissional face ao contexto prisional e as expressões da questão social que se manifestam de forma latente nesse contexto.

Posteriormente, revoga-se a portaria na qual se instituiu o PNSSP que deixava algumas lacunas, principalmente estruturais, e após um longo processo de construção e discussão $^{10}$, foi elaborada a Portaria Interministerial $n^{0} 1$, de 2 de janeiro de 2014 na qual se institui a Política Nacional de Atenção Integral à Saúde das Pessoas Privadas de Liberdade no Sistema Prisional (PNAISP) no âmbito do Sistema Único de Saúde (SUS). Dessa forma tem-se o terceiro marco regulatório referente à atenção à saúde às pessoas privadas de liberdade.

Em relação ao PNSSP, vigente de 2003 a 2013, a atual Política de Atenção à Saúde no Sistema Prisional avança em aspectos como a busca por mais resolutividade das ações de saúde, a vinculação direta aos princípios da atenção primária à saúde, o estabelecimento de equipes de atenção básica à saúde ampliada, no que tange aos profissionais que as compõem, definidas pelo quantitativo da população prisional e funcionamento dos serviços (BRASIL, 2014b). De acordo com Lermen et al. (2015) uma das fragilidades do PNSPP foi não garantir a atenção integral às minorias que compõem o cenário penitenciário, por exemplo às mulheres.

\footnotetext{
${ }^{10}$ Ver Silveira (2015)

Serv. Soc. \& Saúde, Campinas, SP v.15, n. 2 (22), p. 219-242, jul./dez. 2016 ISSN 1676-6806
} 
A PNAISP propõe mudanças na atenção à saúde das pessoas privadas de liberdade estabelecendo junto às demais resoluções e portarias que a regulamentam um novo direcionamento frente à efetivação ao direito à saúde para as pessoas privadas de liberdade. Dessa forma, cabe pontuar a necessidade iminente de estudos e pesquisas que avaliem os serviços de saúde e a implementação da PNAISP. Segundo Neto (2014, slides 15-16) com a nova política de saúde prisional pretende-se avançar nos seguintes aspectos:

Inclusão de todo o itinerário carcerário no SUS; Mudança da lógica de equipes para Serviços de Saúde com remodelagem de equipes por faixas de atenção; Financiamento adequado - cálculo número de consultas/habitante/ano + referencia EMAD + faixas de atenção Resolução CNPCP (ambiência) + compensação estadual e municipal; Equipes de Saúde operando na lógica do SUS: vinculadas às Secretarias Estaduais e Municipais de Saúde, podendo estar vinculadas também à Administração Penitenciária (parte da saúde e parte da justiça); Articulação com a Rede de Atenção à Saúde do território; Observatório Epidemiológico em Saúde no Sistema Prisional; Observatório em Saúde Mental no Sistema Prisional; Política de Educação Permanente para os Trabalhadores em Serviços Penais; Monitoramento e Avaliação da PNAISP; Política Editorial em Saúde no Sistema Prisional.

Na análise da PNAISP realizada por Lermen et al. (2015) pontua-se que

A PNAISP representa um expressivo avanço na atenção à saúde da população prisional, bem como amplia a noção de garantia de direitos sociais. Assim, ao estender o foco anteriormente dado pelo PNSSP, o público-alvo da política abrange a amplitude dessa população, ou seja, todas as pessoas que se encontrem sob custódia do Estado, em regime fechado, semiaberto, aberto ou cumprindo medida de segurança na modalidade de tratamento ambulatorial. Outro avanço advindo da PNAISP é a inclusão de trabalhadores dos serviços prisionais e de familiares de pessoas privadas de liberdade nas ações de promoção e prevenção dos agravos à saúde (ibid., p. 916).

A portaria $\mathrm{n}^{\circ}$ 482, instituída em 1 de abril de 2014, promulgada pelo Ministério da Saúde, apresentará a regulamentação para a operacionalização da PNAISP. Nesse documento são apresentadas e detalhadas as propostas de equipe mínima de acordo com a quantidade de pessoas custodiadas. Além dessa portaria, outros documentos estão em processo de elaboração para regulamentarem assuntos como saúde mental e assistência farmacêutica, por exemplo. Os Estados e Municípios estão em processo de adesão a essa política, de pactuação e formulação para implementá-la. A adesão municipal à PNAISP será facultativa, devendo se observar critérios estabelecidos pela portaria que 
instituiu a atual política de saúde prisional. O processo de adesão à PNAISP se efetivará por meio de acordos estabelecidos entre o Estado e do Distrito Federal com a União. “Os entes federativos terão prazo até 31 de dezembro de 2016 para efetuar as medidas necessárias de adequação de suas ações e seus serviços para que seja implementada a PNAISP [...]” (BRASIL, 2014b).

Em termos de organização dos serviços, a PNAISP remete a atenção em saúde aos pressupostos do Sistema Único de Saúde brasileiro e da atenção básica oferecida pelo município. A atenção básica será ofertada 1) por meio das equipes de atenção básica das unidades básicas de saúde definidas no território ou 2) por meio das Equipes de Saúde no Sistema Prisional (ESP), observada a pactuação estabelecida (BRASIL, 2014b). Dessa forma, expande a atenção às faixas de população prisional. A oferta das demais ações e serviços de saúde será pactuada na Rede de Atenção à Saúde (BRASIL, 2014).

Conforme a portaria $\mathrm{n}^{\circ}$ 482, de 1 de abril de 2014, promulgada pela Ministério da Saúde,

Art. $2^{\circ}$ Os serviços de saúde nos estabelecimentos prisionais serão conformados de acordo com a população prisional e o funcionamento dos serviços, classificando-se em 3 (três) faixas:

I - unidades prisionais que contenham até 100 (cem) custodiados: serviço de saúde com funcionamento mínimo de 6 (seis) horas semanais;

II - unidades prisionais que contenham de 101 (cento e um) a 500 (quinhentos) custodiados: serviço de saúde com funcionamento mínimo de 20 (vinte) horas semanais; e

III - unidades prisionais que contenham de 501 (quinhentos e um) a 1200 (um mil e duzentos) custodiados: serviço de saúde com funcionamento mínimo de 30 (trinta) horas semanais.

Art. $3^{\circ}$ Os serviços de saúde de que trata o art. $2^{\circ}$ serão prestados por equipes multiprofissionais, denominadas Equipes de Saúde no Sistema Prisional (ESP), [...] (BRASIL, 2014c).

O assistente social compõe, obrigatoriamente, as equipes mínimas nas faixas II (Equipe de Atenção Básica Prisional tipo II e Equipe de Atenção Básica tipo II com saúde mental) e III (Equipe de Atenção Básica Prisional tipo III). Na faixa I, para unidades prisionais com até 100 pessoas privadas de liberdade, o assistente social não compõe a Equipe de Atenção Básica Prisional tipo I e fica facultada a escolha desse 
profissional, pela gestão, para compor a Equipe de Atenção Básica Prisional tipo I com saúde mental, conforme pode se observar na Portaria $n^{0} 482$ (BRASIL, 2014c) que apresenta a composição e denominação das Equipes de Saúde Prisional.

As equipes de saúde estabelecidas nas unidades prisionais no Brasil, conforme os moldes da PNSSP, deverão se adequar à nova lógica da política. As equipes de saúde podem ser constituídas totalmente por profissionais servidores efetivos ou contratados pelo município; de forma mista, ou seja, profissionais que possuem vínculo empregatício com o Estado e outros vinculados ao município; e até mesmo por profissionais contratados por empresas terceirizadas. Sendo assim, dependendo da localidade os assistentes sociais dos serviços de saúde poderão ter vínculo empregatício por parte do município, do Estado ou terceirizado. Pode haver unidade do sistema penitenciário gerida por empresa terceirizada, dessa forma os assistentes sociais serão contratados por essas instituições. As equipes de saúde prisional dos municípios que aderiram à PNAISP deverão se adequar à perspectiva proposta pela nova política de atenção à saúde no âmbito do sistema penitenciário a qual exigirá o diálogo com os fluxos organizativos de saúde do município. Um exemplo de adequação discutida atualmente é a utilização por parte das equipes, independente da configuração, do sistema e-SUS da Atenção Básica ${ }^{11}$.

Por fim, outro documento importante que regulamenta os serviços de saúde prisional é a Resolução $n^{\circ}$ 4, de julho de 2014, do Ministério da Justiça, que aprova as Diretrizes Básicas para Atenção Integral à Saúde das Pessoas Privadas de Liberdade no Sistema Prisional. Estas diretrizes básicas se aplicam a quaisquer estabelecimentos que mantenham pessoas privadas de liberdade, em caráter provisório ou definitivo:

2.1. Devem ser contempladas ações de prevenção, promoção e cuidado em saúde, preconizadas na Política Nacional de Atenção Básica (PNAB), constantes na Relação Nacional de Ações e Serviços de Saúde (RENASES), no âmbito do SUS.

\footnotetext{
${ }^{11}$ Segundo o Departamento de Atenção Básica, do Ministério da Saúde, O e-SUS Atenção Básica (e-SUS AB) é uma estratégia do Departamento de Atenção Básica para reestruturar as informações da Atenção Básica em nível nacional. Esta ação está alinhada com a proposta mais geral de reestruturação dos Sistemas de Informação em Saúde do Ministério da Saúde, entendendo que a qualificação da gestão da informação é fundamental para ampliar a qualidade no atendimento à população. A estratégia e-SUS AB, faz referência ao processo de informatização qualificada do SUS em busca de um SUS eletrônico. Disponível em <http://dab.saude.gov.br/portaldab/esus.php> Acesso em 08 abr de 2016. Serv. Soc. \& Saúde, Campinas, SP v.15, n. 2 (22), p. 219-242, jul./dez. 2016 ISSN 1676-6806
} 
2.2. Para a execução das ações de saúde integral, os sistemas prisionais deverão atuar em cooperação com os serviços e equipes do SUS, organizados de acordo com o consignado na norma de operacionalização da PNAISP e na PNAB.

2.3. As administrações prisionais deverão facilitar a implantação das equipes de saúde vinculadas ao SUS, garantindo-lhes as infraestruturas adequadas e segurança suficiente (BRASIL, 2014d).

Considerando a perspectiva do Sistema Único de Saúde na atenção à saúde das pessoas privadas de liberdade, o processo de trabalho em saúde no sistema prisional será permeado por desafios, não só para o assistente social, mas também para todos os profissionais do serviço de saúde. Segundo Coelho et al. (2008),

Dentro dessa perspectiva, os profissionais de saúde que atuam no sistema prisional, pautados nos princípios do Sistema Único de Saúde, vão se deparar com um campo de atuação peculiar. Haverá diversos desafios na construção de ações de saúde de maneira integrada com os demais pontos da rede de atenção, bem como práticas que se afastem do estigma e das discriminações vivenciadas pelas pessoas privadas de liberdade, podendo assim priorizar a escuta e o cuidado integral.

Para transpor esse desafio é necessário conhecer, além das políticas públicas referentes à atenção à população privada de liberdade, quem é essa população no Brasil, como ocorre o processo de trabalho no sistema prisional. Também é preciso conhecer as possibilidades de atenção considerando as diretrizes do SUS, as vulnerabilidades a que mulheres e homens privados de liberdade estão expostos, e como essas questões influenciam no acesso à saúde (ibid., p. 13).

Em decorrência da implementação da atual Política Nacional de Atenção Integral à Saúde das Pessoas Privadas de Liberdade e suas regulamentações é necessário pontuarmos aspectos elementares para se pensar a inserção dos assistentes sociais nas Equipes de Saúde do Sistema Prisional (ESP), preconizadas pela PNAISP.

\section{BREVES APONTAMENTOS PARA A CONCEPÇÃO DO SERVIÇO SOCIAL NA SAÚDE PRISIONAL NOS MOLDES DA PNAISP}

Permeados por esses momentos históricos materializados nas três legislações mencionadas anteriormente e pelo processo histórico de construção do Sistema único de Saúde no Brasil, a Política Nacional de Atenção Integral à Saúde das Pessoas Privadas de Liberdade (PNAISP), a partir das equipes de atenção à saúde prisional, promove a abertura de uma nova lógica de atuação profissional, no âmbito prisional. 
Matos (2013) pontua uma importante reflexão no sentido de contribuir para se compreender a particularidade do trabalho do assistente social na saúde que se torna fundamental nesse estudo:

O ponto de partida para a compreensão desta reflexão é o reconhecimento de que os assistentes sociais quando lidam com a política de saúde, mediatizada pela sua operacionalização nos serviços de saúde, não desenvolvem no seu exercício profissional nenhum procedimento interventivo ou mesmo conhecimento que só sirva e se explique para a atuação na área da saúde. Contudo, mesmo não havendo uma atuação ou saber exclusivos do Serviço Social nesta área - como também em nenhuma área das políticas setoriais - há no exercício profissional na saúde particularidades [...] (ibid., p. 63).

O profissional deve apreender o Serviço Social em seus aspectos teóricometodológico, ético-político e técnico-operativo, a partir de um olhar crítico da conjuntura. Dessa forma, ampliará sua capacidade de analisar e intervir na realidade através de ações com direcionamentos que possibilitem a construção de uma sociedade com uma cultura oposta à perspectiva repressora e punitiva muito presente no sistema penitenciário.

No sentido de analisar a metamorfose dos espaços ocupacionais do assistente social, no qual o serviço de saúde no âmbito prisional é um deles, Iamamoto (2009, p. 357-358, apud OLIVEIRA; SALLES, 1998; BRAVO, 1996; PEREIRA, 1998) propõe uma análise de conjuntura essencial para a inserção do assistente social nesse espaço:

As estratégias para responder à questão social têm sido tensionadas por projetos partidários e político-institucionais distintos, que presidem a estruturação legal e a implementação das políticas sociais públicas desde o final dos anos oitenta, e convivem em luta no seu interior. Vive-se uma tensão entre a defesa dos direitos sociais universais e a mercantilização e refilantropização do atendimento às necessidades sociais, com claras implicações nas condições e relações de trabalho do assistente social.

É de suma importância ao assistente social compreender que sua prática profissional está inserida em uma sociedade contraditória, em um jogo de tensões e disputas societárias. A relação do assistente social no contexto da saúde com as perspectivas da justiça e do sistema penitenciário expressa tensionamentos e projetos societários distintos. 
Nessa perspectiva Lermen et al. (2015, p. 917 e 919) propõe a seguinte reflexão:

Ao refletirmos sobre as características da sociedade no período em que a PNAISP surge - ou seja, atualmente -, deparamo-nos com uma configuração profundamente contraditória no âmbito dos direitos sociais. Ao mesmo tempo em que se tem conquistada uma política social de saúde com ampla garantia desse direito à população privada de liberdade, crescem os debates acerca da redução da maioridade penal. [...]

O pensamento meritocrático, vinculado ao cidadão trabalhador e somado a um sistema prisional falido em sua função de ressocialização, faz com que muitas das ações que visam atingir a população prisional encontrem resistências para a sua real efetivação.

Barsaglini et al. (2015, p. 1119-1120) propõe uma análise sobre a gestão da política de saúde; desse estudo tem-se um importante apontamento, complementar a reflexão anterior, que caracteriza as relações institucionais as quais incidem nos profissionais de saúde das equipes de atenção básica prisional:

A gestão das ações de saúde penitenciária encontra entraves, mas, também, avanços. Ressaltam-se as incongruências nos valores que regem o setor da justiça e o da saúde, em que questões jurídicas, de segurança e disciplina tensionam o direito à saúde e a superlotação não pode ser ignorada. $\mathrm{O}$ contexto prisional imprime peculiaridades à assistência que se refletem na gestão, pois ora empreendem-se adequações frente ao diferente mobilizando o princípio da equidade, ora o compromete colocando os gestores diante de dilemas entre o cuidado necessário e o possível.

Os assistentes sociais precisam se apropriar dessas discussões para desvelar as possibilidades da realidade e caminhar em um processo de construção de uma lógica do direito que vá de encontro a práticas coercitivas e autoritárias que são latentes no contexto prisional.

Nesse sentido uma ação fundamental do exercício profissional é conhecer as relações institucionais das unidades prisionais, o território, as relações sociais e o cotidiano dos usuários, agentes prisionais e familiares das pessoas privadas de liberdade, compreender a política de saúde, os normativos e procedimentos da unidade prisional, os fluxos de atenção em saúde dos municípios e a rede socioassistencial. Em análise aos desafios dos profissionais de saúde no sistema prisional, Coelho et al. (2014), complementam apontando que

[...] é necessário conhecer, além das políticas públicas referentes à atenção à população privada de liberdade, quem é essa população no Brasil, como ocorre o processo de trabalho no sistema prisional. 
Também é preciso conhecer as possibilidades de atenção considerando as diretrizes do SUS, as vulnerabilidades a que mulheres e homens privados de liberdade estão expostos, e como essas questões influenciam no acesso à saúde (ibid., p.13).

Um importante direcionamento à atuação profissional no cotidiano de trabalho em saúde no âmbito prisional é identificar aspectos sociais, culturais, econômicos que incidem no processo saúde-doença das pessoas privadas de liberdade do território e conceber estratégias para o enfretamento dessas questões que são oriundas da questão social (MATOS, 2013). Esse espaço sócio-ocupacional, como mencionado anteriormente, é um lócus de tensão de projetos societários e profissionais bem como da manifestação das expressões da questão social, como por exemplo, a violência.

A atuação do Serviço Social nesse contexto da saúde prisional deve ser concebida e construída a partir dos parâmetros de atuação do assistente social na política de saúde, não sendo sua atuação direcionada e balizada apenas por orientações e normativos do Estado e da Lei de Execução Penal. Dessa forma, devem ser consideradas a lógica da concepção de saúde preconizada pela reforma sanitária brasileira, a elaboração coletiva do processo de trabalho de saúde e o conhecimento territorial a partir de um diagnóstico situacional. Além disso, é fundamental, antes de tudo, pensar em uma atuação arraigada nos pressupostos teórico-metodológico, éticopolítico e técnico-operativo, constituídos historicamente na profissão (IAMAMOTO, 1992).

\section{CONSIDERAÇÕES FINAIS}

Ao se pensar na atenção à saúde de pessoas privadas de liberdade proposta pela atual política de saúde no âmbito prisional estabelece-se a necessidade de não só um diálogo interministerial, mas também um diálogo e pactuações entre municípios e Estados os quais são fundamentais na elaboração conjunta de um serviço de saúde voltado a essa população, cada qual com suas atribuições, no território. Os desafios da atual política de atenção prisional são, entre outros, estabelecer esse diálogo e adequar os serviços de saúde prisional ou implementá-los considerando a nova perspectiva de atenção à saúde vinculada à atenção primária. Ao se tratar dessa temática torna-se necessário ao Serviço Social compreender o sistema penitenciário brasileiro, pois os 
serviços de saúde de atenção à saúde prisional, em sua maioria, estão inseridos nos presídios e nas penitenciárias.

O assistente social que compõe o trabalho coletivo em saúde, marcado por práticas interdisciplinares e caráter multiprofissional deve lançar mão de uma concepção ampliada de saúde e estabelecer bem como estruturar junto à equipe de saúde um processo de trabalho não focado na doença ou no diagnóstico, estabelecendo um caminho contrário à perspectiva biomédica tão presente nos primórdios da inserção do assistente social na saúde. Assim como preconiza o Código de Ética Profissional no que tange as relações dos assistentes sociais com outros profissionais, o profissional inserido nas equipes de saúde no contexto do sistema prisional deve "incentivar, sempre que possível, a prática profissional interdisciplinar” (BRASIL, 2012b, p. 33).

Frente a um contexto de autoritarismo, marcantes no sistema penitenciário, a apreensão dos princípios do Código de Ética Profissional é imprescindível para se propor ações interdisciplinares que caminham ao encontro do projeto ético-político profissional, principalmente tendo como norte a liberdade como valor ético central, ampliação e consolidação da cidadania, defesa intransigente dos direitos humanos e recusa do arbítrio e do autoritarismo o constante aprimoramento intelectual (BRASIL, 2012b, p. 23-24).

A atual Política de Saúde Prisional está em fase de implementação e trouxe uma nova perspectiva e transformações no direcionamento à atenção à saúde das pessoas privadas de liberdade, principalmente na efetivação do direito à saúde a qual "requer o rompimento com a lógica punitiva de encarceramento da sociedade disciplinar”, além “da garantia de acesso às ações e aos serviços públicos e estatais de saúde” (MARTINS et al., 2014, p. 1232). Desde a instituição do primeiro marco legal que instaurou uma proposição para a atenção à saúde das pessoas privadas de liberdade o aspecto da efetivação do direito à saúde tem-se transformado historicamente. Atualmente a PNAISP permite uma ampliação ao se tratar do direito à saúde. Nesse sentido põe ao Serviço Social novos desafios e uma perspectiva de trabalho voltada ao campo da saúde o qual deve ser acompanhados pelos pressupostos do projeto ético-político profissional.

Apesar dos avanços históricos materializados na PNAISP e demais regulamentações frente ao acesso e garantia do direito à saúde desse grupo 
populacional, é necessário compreender a contradição presente na sociedade capitalista que permite avanços e retrocessos de direitos.

Permeado pelo histórico da construção do SUS, pelo processo histórico do Serviço Social na relação com a saúde e pelos três marcos regulatórios fundamentais na atenção à saúde prisional, a Política Nacional de Atenção Integral à Saúde das Pessoas Privadas de Liberdade, a partir das equipes de atenção à saúde prisional, promove a abertura de uma nova lógica de atuação profissional, no âmbito prisional, constituindose um campo a ser avaliado, desvendado, problematizado e discutido.

Recebido em 19.09.2016 - Aprovado em 19.12.2016

\section{REFERÊNCIAS}

BARSAGLINI, R.A.; KEHRIG, R.T.; ARRUDA, M.B. Análise da percepção de gestores sobre a gestão da política de saúde penitenciária em Mato Grosso, Brasil. Saúde e Sociedade. São Paulo, v.24, n.4, p.1119-1136, 2015.

BRASIL. Código de ética do/a assistente social. Lei 8.662/93 de regulamentação da profissão. - 10a . ed. rev. e atual. [Brasília]: Conselho Federal de Serviço Social, 2012b. BRASIL. Constituição Federal. Constituição da República Federativa do Brasil. promulgada em 5 de outubro de 1988. Brasília, DF: Senado, 1988. Disponível em: <http://www.planalto.gov.br/ccivil_03/constituicao/constituicaocompilado.htm>. Acesso em: 18 nov. 2016.

BRASIL. Ministério da Saúde. Política Nacional de Atenção Básica. Brasília: Ministério da Saúde, 2012a. (Série E. Legislação em Saúde). 110 p. Disponível em: $<$ http://dab.saude.gov.br/portaldab/biblioteca.php?conteudo=publicacoes/pnab $>$. Acesso em: 1 jul. 2015.

BRASIL. Lei n ${ }^{\circ}$ 7.210, de 11 de julho de 1984. Institui a Lei de Execução Penal. Brasília, DF. 1984. Disponível em:

<http://www.planalto.gov.br/ccivil_03/Leis/L7210.htm>. Acesso em: 18 nov. 2016. BRASIL. Ministério da Justiça. Conselho Nacional de Política Criminal e Penitenciária. Resolução nº4, de 18 de julho de 2014. Diário Oficial da República Federativa do Brasil, Brasília, DF, no 139, 23 jul 2014d. Seção 1, p.38. Serv. Soc. \& Saude, Lampinas, SP v.15, n. 2 (22), p. 219-242, jul./dez. 2016 ISSN 16/6-6806 
BRASIL. Ministério da Justiça. Departamento Penitenciário Nacional - Ministério da Justiça. Levantamento Nacional de Informações Penitenciárias INFOPEN, 2014a. Disponível em: < $\underline{\text { https://www.justica.gov.br/noticias/mj-divulgara-novo-relatorio-do- }}$ infopen-nesta-terca-feira/relatorio-depen-versao-web.pdf $>$. Acesso em: 17 nov. 2016. BRASIL. Ministério da Saúde. Plano Nacional de Saúde do Sistema Penitenciário. $1^{\text {a }}$ ed, Brasília, DF. 2004. 64 p.

BRASIL. Ministério da Saúde. Portaria Interministerial n. ${ }^{\circ}$ 1, de 2 de janeiro de 2014. Institui a Política Nacional de Atenção Integral à Saúde das Pessoas Privadas de Liberdade no Sistema Prisional (PNAISP) no âmbito do Sistema Único de Saúde (SUS). Diário Oficial da República Federativa do Brasil, Brasília, DF, n 2, 3 jan 2014b. Seção 1, p.18.

BRASIL. Ministério da Saúde. Portaria nº482, de 1 de abril de 2014. Institui normas para a operacionalização da Política Nacional de Atenção Integral à Saúde das Pessoas Privadas de Liberdade no Sistema Prisional (PNAISP) no âmbito do Sistema Único de Saúde (SUS). Diário Oficial da República Federativa do Brasil, Brasília, DF, nº 63, 2 abril 2014c. Seção 1, p.48.

COELHO, E. B. S et al. (Org.). Atenção à saúde das pessoas privadas de liberdade [recurso eletrônico]: apresentação do curso. Curso de Atenção à Saúde das Pessoas privadas de Liberdade - Modalidade a Distância. Florianópolis: Universidade Federal de Santa Catarina, 2014. 36 p. Modo de acesso:

$<$ https://unasus.ufsc.br/saudeprisional/>.

FLEURY, S.; OUVERnEY, A. M. Política de Saúde: Uma Política Social. Políticas e Sistemas de Saúde no Brasil. GIOVANELLA, L; ESCOREL, S; LOBATO, L.V.C; NORONHA, J.C; CARVALHO, A.I. (Org.) 2 a Ed. Rio de Janeiro: Editora Fiocruz/Centro Brasileiro de Estudos de Saúde; 2012. 1100p.

GIL, C. R.R. Atenção Primária, atenção básica e saúde da família: sinergias e singularidades do contexto brasileiro. Caderno Saúde Pública, Rio de Janeiro, 22(6):1171-1181, jun, 2006.

IAMAMOTO, M. V. Os espaços sócio-ocupacionais do assistente social. Serviço Social: direitos sociais e competências profissionais. Brasília: CFESS/ABEPSS, 2009, p. 341-375.

IAMAMOTO, M. V. Renovação e conservadorismo no Serviço Social. Ensaios críticos. São Paulo: Cortez, 1992

Serv. Soc. \& Saúde, Campinas, SP v.15, n. 2 (22), p. 219-242, jul./dez. 2016 ISSN 1676-6806 
KRUGER, T. R.; MOSCON, N. O Serviço Social na Atenção Básica e o Acesso aos Serviços de Saúde. Revista de Saúde Pública de Santa Catarina, Vol. 3, No 2. 2010b. KRUGER; T. R. Serviço Social e Saúde: Espaços de atuação a partir do SUS. Serviço Social \& Saúde. UNICAMP Campinas, v. IX, n. 10, Dez. 2010a.

LERMEN, H. S et al. Saúde no cárcere: análise das políticas sociais de saúde voltadas à população prisional brasileira. Physis [online], Rio de Janeiro, vol. 25, n.3, p. 905-924, 2015.

MARTINS, E. L. C. et al. O contraditório direito à saúde de pessoas em privação de liberdade: o caso de uma unidade prisional de Minas Gerais. Saúde \& Sociedade. São Paulo, v.23, n.4, p.1222-1234. 2014.

MATOS, M. C. Serviço Social, ética e saúde: reflexões para o exercício profissional. São Paulo, Cortez, 2013. 168p.

MIOTO, R. C. T.; NOGUEIRA, V. M. R. Sistematização, planejamento e avaliação das ações dos assistentes sociais no campo da saúde. MOTA, A. E. et al. (Org.). Serviço Social e Saúde: formação e trabalho profissional. São Paulo: OPAS, OMS, MS, Cortez, 2006, p. 273-303.

NETO, F. J. Política Nacional de Atenção à Saúde das Pessoas Privadas de Liberdade no Sistema Prisional. Acesso e Regulação no SUS: Desafios da Concretização do SUS Constitucional. Encontro de Gestores de Saúde Prisional do Estado de Santa Catarina. Palhoça/ SC. Abril, 2014. 25 slides. Disponível em:

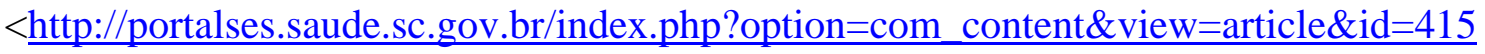
3:apresentacoes-encontro-estadual-de-gestores-de-saude-e-do-sistemaprisional\&Itemid=618> Acesso em: 8 abr de 2016.

SILVEIRA, N. O. A trajetória da Saúde Prisional no Brasil. Porto Alegre: UFRGS, 2015. 31 f. Trabalho de conclusão de curso (especialização em Saúde Pública) Departamento de Medicina Social, Faculdade de Medicina, Universidade Federal do Rio Grande do Sul, Porto Alegre, 2015.

SOUZA, M. C. P et al. Atenção à saúde no sistema penitenciário: revisão de literatura. Revista Interdisciplinar. v. 6, n. 2, p. 144-151, abr./mai. jun. 2013. VASCONCELOS, C. M.; PASCHE, D. F. O Sistema Único de Saúde. CAMPOS, G. W. S. et al. (Org.). Tratado de Saúde Coletiva. São Paulo: Hucitec; Rio de Janeiro: Fiocruz, 2006. p. 531-562. 
